\title{
Resenha
}

\section{A Estabilização em Dois Registros ${ }^{\star}$}

\author{
- Patrícia Helena f. Cunha*
}

\begin{abstract}
RESUMO
O objetivo deste artigo é registrar a contribuição e evolução da concepção de Persio Arida sobre a estabilização da inflação alta e crônica experimentado pela economia brasileira. Ele foi um participante importante do esforço coletivo de formulação do Plano Cruzado e Plano Real. Inicialmente a estabilização heterodoxa, com moeda indexada, foi apresentada como uma proposta superior às outras alternativas em decorrência de duas características muito salientadas: o programa de estabilização seria quase indolor e regido pelo princípio da neutralidade. No entanto, tanto a neutralidade como a ausência de custos serão concepções abandonadas em suas reflexões após várias tentativas fracassadas de estabilização no Brasil.
\end{abstract}

Palavras-CHave

estabilização de preços, inflação alta, moeda indexada, princípio da neutralidade, liquidez excessiva da dívida

\section{ABSTRACT}

This paper explores the contribution and evolution of Persio Arida concept about the stabilization of high and chronic inflation in the Brazilian economy. He was an important economist of the team responsible for the formulation of Cruzado Plan and Real Plan. In the beginning, the heterodox stabilization with indexed money was presented as better than others stabilizations alternatives because of two stressed characteristics: the stabilization program would be almost painless and guided by the neutrality principle. However, both the neutrality and almost painless notions will be abandoned in yours reflections after several failed stabilizations in Brazil.

\section{KEY WORDS}

price stabilization, high inflation, indexed money, neutrality principle, excess liquidity debt

\section{JEL CLASSIFICATION}

$N 16, E 65, B 3 I$

- A autora agradece os valiosos comentários de Persio Arida, José Márcio Rego e Paulo Gala. Os erros e omissões são de inteira responsabilidade da autora.

* Departamento de Economia da Pontifícia Universidade Católica - PUC, São Paulo. E-mail: pcunha@pucsp.br. Endereço para contato: Rua Ministro de Godói, 969 - 4o. andar, sala 4E-17 - Perdizes - São Paulo, SP - CEP: 05015-901.

(Recebido em agosto de 2004. Aceito para publicação em julho de 2005). 


\section{INTRODUÇÃO}

Persio Arida participou do esforço coletivo de formulação de política de estabilização em dois momentos especialmente marcantes de nossa história econômica recente: fez parte da equipe responsável pela elaboração do Plano Cruzado em 1986 e do bemsucedido Plano Real em 1994. O que se mostra singular nesta trajetória é a presença da mesma base conceitual nos dois Planos, ou seja, o diagnóstico da inflação inercial, apesar da solução experimentada em 1986 não ser a proposta "Larida". ${ }^{l}$ Esta última propunha estabilizar a inflação brasileira por meio de uma reforma monetária com indexação plena, estratégia que acabou sendo adotada no Plano Real.

Arida (1999) identifica como quatro os princípios da proposta "Larida"2 que nortearam o plano de 1994: o pré-anúncio do programa, a introdução da moeda alternativa na fase de transição, a livre conversão de contratos para a nova moeda via mercados, o uso da reforma monetária como instrumento para remover a inércia inflacionária. Ressalta somente duas diferenças do Plano Real com a proposta "Larida": a moeda indexada existiu apenas virtualmente na fase de transição; e o papel atribuído à âncora dos preços. A crise da dívida externa de 1982, e sua conseqüente restrição à liquidez internacional, impossibilitavam a adoção do câmbio para esse papel.

A leitura de seus artigos de $1984 / 85^{3}$ mostra que o paradigma inercial apresentava a estabilização heterodoxa com moeda indexada como uma proposta superior às outras alternativas então debatidas em decorrência de duas características muito salientadas: o programa de estabilização seria quase indolor e regido pelo princípio da neutralidade. Vale destacar que essas características foram questionadas e reelaboradas em sua Tese de Doutoramento de 1992, quando ele se debruçou sobre as experiências malsucedidas de estabilização no Brasil. Assim, a partir deste novo esforço analítico sobre como combater as inflações altas e crônicas, identificada como inflação inercial, desaparece o discurso da reforma monetária branda e neutra. Para lidar com a questão da liquidez excessiva da dívida pública, duas alternativas são apresentadas: uma, de consolidação; e a segunda, a que acabou sendo adotada no Plano Real, de adoção de altas taxas de juros.

Cabe salientar um traço marcante na formação intelectual de Arida, e fundamental para a compreensão do teórico bem como do formulador e operador de política: a sua preocupação com o método. O seu texto sobre Retórica ${ }^{4}$ é um marco nas discus-

1 Apelido dado por Rudiger Dornbusch, a proposta apresenta em paper conjunto de Pérsio Arida e André Lara Resende em 1984 numa conferência internacional organizada por John Williamson. (Arida e Lara Resende, 1984).

2 Não há disputa entre Arida e Lara Resende sobre quem teria a primazia sobre a idéia.

3 Arida $(1984,1985)$ Arida e Lara Resende (1985).

4 Arida (1996). 
sões acadêmicas brasileiras. Ele argumenta que as controvérsias travadas em teoria econômica não são resolvidas submetendo as teorias às evidências empíricas, mas sim por meio da Retórica, da capacidade de persuadir, argumentar e convencer os participantes, tanto nos embates internos a cada tradição quanto entre as diferentes tradições teóricas. ${ }^{5}$

Apesar de não ser nosso objetivo realizar uma análise Retórica da contribuição de Arida, mas apenas identificar essa característica nos seus trabalhos, parte-se da suposição de que as duas fases analíticas de discussão de problemas de teoria e política sobre a estabilização da economia brasileira identificadas acima estão impregnadas da percepção de Arida acerca da necessidade de convencer e persuadir. Inicialmente porque a estratégia de estabilização defendida era uma novidade ousada e desafiava o saber econômico convencional, conseqüentemente, exigia uma solução heterodoxa. Depois, no segundo momento, a teoria e política associadas à estabilização continuam ousadas, mas o seu sucesso depende da convicção política de fazê-lo.

O objetivo deste artigo é registrar esses dois momentos de nossa história econômica recente por meio da discussão de Arida sobre questões de estabilização da inflação alta e crônica experimentada pela economia brasileira, enfatizando a dimensão teórica dessa discussão. Assim, daremos ênfase à leitura de duas fases dos trabalhos acadêmicos de Arida: a primeira, de 1984/85, quando ele publica a maioria dos papers que originariam a proposta de moeda indexada, e o segundo, a tese de doutoramento de 1992, quando Arida vai estudar as experiências malsucedidas no Brasil para entender as especificidades da economia brasileira e aprimorar sua proposta. O destaque atribuído ao aspecto político é apreendido principalmente na entrevista concedida a Biderman, Cozac e Rego (1996).

\section{OS “MÁGICOS” VENDENDO A ESTABILIZAÇÃO}

O ano de 1984 foi especialmente importante para o debate econômico brasileiro. A elevação das taxas de inflação, em um período de transição política, permite entender o debate acalorado que extravasou os limites da academia. Em 1985 tomaria posse na Presidência da República o primeiro civil depois de 20 anos de presidentes militares. As eleições foram indiretas, mas a coalizão vencedora, em grande parte, emergiu da oposição ao regime anterior.

5 Para substanciar a sua tese, Arida discute dois modelos estilizados de aprendizado da História do Pensamento Econômico e da Teoria Econômica: soft science e hard science. Seu objetivo é criticar ambos os modelos, mostrando suas inadequações para explicar o progresso em Economia, e assim apresentar sua tese de que as controvérsias na Ciência Econômica se resolvem por meio da Retórica, de acordo com algumas regras relativamente consensuais. 
Foi da PUC-Rio que saíram as principais propostas alternativas de combate à inflação: o choque heterodoxo e reforma monetária. Ambas partiam do mesmo diagnóstico do processo inflacionário: a inflação inercial. Francisco Lopes ${ }^{6}$ havia inicialmente proposto o choque heterodoxo com congelamento geral de preços e salários. Persio Arida e André Lara Resende sugeriam a reforma monetária passando por uma indexação total da economia. Ou seja, propunham repetir o caminho de uma hiperinflação sem passar pela traumática experiência de uma hiperinflação. Outros economistas de oposição ao regime militar e de sua política econômica estavam espalhados pelo Brasil, mas mais concentrados em São Paulo e Rio de Janeiro, na Unicamp, FGV/SP, USP e UFRJ. Mas nestes outros centros o debate era mais difuso. Cabe lembrar que o regime militar produziu uma fragmentação entre os economistas. Sob a denominação de oposição encontrava-se um conjunto bastante amplo de visões sobre os problemas econômicos e, portanto, em como solucioná-los. A heterogeneidade da equipe econômica responsável pela implementação do Plano Cruzado revelou com clareza este fato. ${ }^{7}$

Para entender os aspectos destacados por Arida nos seus textos de 1984/85 de neutralidade e da estabilidade quase sem custo é importante resgatar a construção de seu argumento.

Mas, antes da exposição dos argumentos de Arida, convém chamar a atenção para essa forma de apresentação. Segundo Fernandez,

"la posibilidad de que diversas explicaciones puedan ser plausibles, sin que haya una base segura para el conocimiento que pueda garantizar cuál es la correcta, la unica forma de elegir entre ellas es que sus proponentes argumenten intentando mostrar las virtudes de sus ideas (y los problemas de las ajenas). En ese marco, la retórica vuelve a ser un elemento central en la reflexión filosófica." (Fernandez, 1999, p. 291).

Tanto no paper escrito enquanto foi Scholar no Woodrow Wilson International Center no final de 1984 quanto no seu trabalho conjunto com Lara Resende ${ }^{8}$ há o objetivo de demonstrar, a partir do diagnóstico de inflação inercial, a superioridade da solução de uma reforma monetária com a introdução de uma moeda indexada. Para mostrar a validade da sua tese, depois de convidar o leitor a aceitar idéias novas e criativas e abandonar velhos conceitos, são discutidas uma a uma as propostas existentes de estabilização, e apresentadas sua refutação. Desta forma, o autor tenta sempre reforçar o seu argumento a favor da reforma monetária por meio da introdução de uma moeda indexada. Por fim, tece considerações sobre a viabilidade política da sua proposta.

6 Lopes (1984).

7 Sola (1988) e Bier, Messemberg e Paulani (1987).

8 Arida (1984). 
Arida começa o seu artigo chamando a atenção para alguns aspectos. De um lado, sublinha o fato de que uma política econômica de estabilização de curto prazo, cujo objetivo é tratar de questões de dívida pública, déficit fiscal, inflação, taxas de juros e câmbio, requer a adoção de uma perspectiva de longo prazo. Afinal, constatava que o modelo de crescimento dos anos 1970, substituição de importaçóes liderado pelo Estado, estava esgotado e um novo modelo ainda não havia se consolidado. De outro, como decorrência, alertava que a tarefa não era simples: "Essa dificuldade é para ser interpretada como sugerindo a necessidade de idéias e soluçôes criativas, se o novo modelo está para acontecer. A unissonáncia mascarada que se difunde muito nas discussóes de politica no Brasil precisa ser removida." (1984, p. 2). Segundo Arida, a crise do Brasil nos anos 1980 se apresenta como problemas novos. A crise da dívida externa e a inflação alta e crônica requerem o desapego às velhas crenças e exigem novas abordagens e, conseqüentemente, soluções criativas por mais paradoxais que possam parecer. Seu argumento para justificar medidas pouco convencionais, como reformas monetária e da dívida externa, para a política econômica é justificada pela sua crença na irreversibilidade do tempo histórico.

Cabe lembrar que no final da década de 1970 a economia brasileira esteve sujeita a sucessivos choques (petróleo e da taxa de juros), bem como à redução na periodicidade dos ajustes salariais e sua recomposição pelo pico, que levaram a inflação para um patamar de 100\% ao ano. A despeito da recessão promovida entre 1981-1983, houve um incremento das taxas de inflação para $200 \%$ ao ano, também como desdobramento da desvalorização cambial.

A partir dessa constatação da resistência das taxas de inflação a medidas de austeridade, Arida e Lara-Resende identificam pelo menos cinco interpretações para explicar tal fenômeno. ${ }^{9}$ E ainda chama de inapropriadas as interpretações que se baseiam no diagnóstico ortodoxo de que o déficit público é a causa da inflação. Antes de enumerá-las é importante perguntar por que ele as julga inapropriadas? Percebe-se que seu principal argumento não é a falta de eficácia, mas sim devido ao elevado custo em termos de produto e emprego das políticas ortodoxas de estabilização. Quanto às abordagens que reconhecem o caráter inercial da inflação e recomendam medidas de desindexação, sua principal discordância é com o fato de o princípio da neutralidade não ser respeitado. Ou, dito de forma mais clara, um programa de estabilização não deve promover distribuição de renda.

Inicialmente, ele destaca que os analistas ortodoxos não perceberam que a indexação dos títulos públicos inverte a causalidade entre déficit e inflação. Neste contexto, a inflação pode causar o déficit, uma vez que os títulos públicos são indexados e, assim, quanto maior a taxa de inflação maior será o déficit no conceito nominal. Entretanto,

9 Arida e Lara Resende (1985). 
na sua exposição reconhece que as políticas ortodoxas podem até funcionar, e apresenta um exemplo, que não deveria ser seguido. O caso chileno mostra que a estratégia ortodoxa funciona, mas apenas em regimes de exceção e com elevados custos econômicos e sociais, impensáveis num período de transição democrática. O Chile, sob a ditadura Pinochet, promoveu uma recessão que redundou em queda do produto de cerca de $15 \%$ e taxas de desemprego ao redor de $22 \%$ em 1982.

\section{Diferentes Terapias para Estabilizar}

A primeira interpretação está baseada na visão ortodoxa da inflação, e atribui a resistência da inflação às medidas restritivas e à falta de persistência da política. Seus defensores afirmam que estas só surtiriam efeito após alguma defasagem de tempo, na medida em que primeiro se verificaria a queda do produto e numa segunda fase a inflação se reduziria. A discordância de Arida está no que ele chama de indeterminação da defasagem temporal, o que o leva a afirmar que "esta abordagem simplesmente oferece um ato de fé e não uma base sólida para a politica econômica." (Arida e Lara Resende, 1985 , p. 5).

A segunda abordagem afirma que não houve medidas de austeridade monetária, e fundamentam seu argumento apontando a necessidade de ampliar o conceito de moeda para mostrar sua correlação com a inflação. Para Arida, estes analistas se baseiam "na crença dogmática de que não bá inflação sem um déficit fiscal subjacente financiado por expansão monetária." (Arida e Lara Resende, 1985, p. 5). Os contra-argumentos apresentados são dois. De um lado, a eliminação do déficit no conceito operacional é condição necessária, porém não suficiente. De outro, que sempre há a possibilidade de encontrar um agregado monetário mais amplo altamente correlacionado com a inflação.

Uma outra interpretação, chamada de enfoque "psicológico", destaca o papel das expectativas, e se inspira no fim abrupto dos casos de hiperinflação. ${ }^{10}$ Neste caso, a razão para a persistência da inflação está na falta de credibilidade das autoridades monetárias na sinalização de mudança de regime. Por trás da ênfase no processo de formação de expectativas encontra-se toda uma literatura sobre credibilidade das políticas econômicas, que no caso de um plano de estabilização envolve a confiança dos agentes econômicos na determinação do governo em combater a inflação, levando muitas vezes a conclusões que parecem relativamente óbvias: um programa de estabilização só será bem-sucedido se for crível. Aqui, a discordância foi apontada na não observância de especificidades importantes da economia brasileira, a saber: a indexação formal e informal existente. Assim, não basta ter credibilidade para alcançar a estabilização.

10 Sargent (1986). 
Segundo Arida, o significado atribuído às propostas de desindexação era variante entre seus proponentes. Ia da escolha de um dia " $D$ " para estabelecer legalmente a indexação igual a zero até propostas de desindexação gradual. Dentro desta lógica, uma quarta abordagem é apresentada, o "choque ortodoxo", que partia também do diagnóstico convencional de que o déficit público é a causa das elevadas taxas de inflação. Assim, as prescrições sugeridas eram: o controle rígido da oferta monetária, o corte do déficit público, liberalização do sistema de preços e a eliminação de todos os mecanismos formais de indexação. Ou seja, uma forte recessão para combater a inflação, além da intensa alteração de preços relativos, que violava o princípio da neutralidade, uma vez que todos os contratos são indexados.

O último enfoque apresentado é o choque heterodoxo, que reconhece o caráter inercial da inflação brasileira. Diferencia-se da abordagem anterior ao propor o rompimento da inércia via controles administrativos e não pela administração da demanda conforme proposto no choque ortodoxo.

O choque heterodoxo, apesar do diagnóstico correto, introduzia medidas de controle administrativo, principalmente o congelamento, para romper a inércia, o que inevitavelmente congelaria os preços relativos em uma situação de desequilíbrio. Assim, apresenta a desvantagem da não neutralidade em termos distributivos. Ressalta-se que o mecanismo de funcionamento da indexação dos salários e dos ativos ocorre de forma muita distinta, principalmente quando se pensa em termos de proteção que a indexação fornece. Além disso, não há impedimento para os agentes indexarem informalmente, só que, mais uma vez, a capacidade de indexação dos agentes é distinto.

Diante dos problemas quanto ao custo e a neutralidade das propostas apresentadas e das lições dos casos históricos de hiperinflação, Arida chega à conclusão que chama de "resultado paradoxal": a melhor forma de desindexar é indexar tudo, da forma mais perfeita possível. É na hiperinflação que se está mais próximo da indexação perfeita, e então uma desindexação sem custo é factível. A hiperinflação traz o germe de sua própria destruição. Assim, a reforma monetária seria a forma de fazer a transição para uma hiperinflação sem passar pelo traumático processo de hiperinflação aberta, estando garantida a neutralidade distributiva.

Na proposta de choque heterodoxo reconhece o mérito de eliminar o componente inercial da inflação por meio do congelamento de salários nominais, taxa de câmbio e preços. No entanto, Arida previa grandes dificuldades na administração do congelamento. Destaca que o principal obstáculo ao congelamento geral era a ausência de sincronização nos reajustes dos diversos preços e salários. Acredita que este só teria chances de ser bem-sucedido se fosse implementado com um pacto social forte. 
Arida argumenta que reforma monetária, via emissão de uma moeda indexada, é uma proposta mais efetiva que o congelamento, no sentido de eliminar a memória inflacionária. O mecanismo funcionaria com a indexação de todos os contratos pelo mesmo índice de preços e para a mesma unidade de tempo, esta a menor possível. A garantia da neutralidade é dada pela conversão dos contratos pelo valor médio do período anterior. Caso fosse convertido pelo valor de pico do contrato, a inflação explodiria, pois haveria uma incompatibilidade distributiva. Assim, a memória do sistema econômico seria toda sincronizada para um mês, como acontece no final do processo de hiperinflação. Uma vez feita a conversão, a reforma monetária envolveria a emissão de uma nova moeda, unindo duas funções da moeda que se encontram separadas, durante uma fase de transição. Como as pessoas tendem a se livrar da moeda antiga, "a inflação vai para zero pela simples razão que, medida em termos de moeda indexada, os preços dos bens e serviços estão constantes." (Arida, 1984, p. 12). Constata ainda uma vantagem na sua proposta, pois se o governo não oferecer uma moeda indexada, perde-se a oportunidade de obter receita de senhoriagem, na medida em que os agentes privados fugiriam da moeda nacional que deprecia, e utilizariam o dólar, inicialmente como unidade de conta e, no final, até para desempenhar a função de meio de troca.

Cabe destacar que a reforma monetária elimina apenas o componente inercial de inflação. Se as taxas de inflação estiverem se acelerando, elas continuariam aumentando depois da reforma. No caso brasileiro, a inércia existe por causa da indexação formal e informal em interação com a fixação de salários e contratos financeiros de forma descontínua. Na verdade, Arida sublinha que a inércia advém de várias fontes, mas enfatiza o fato de "não depender da passividade da moeda e não violar o postulado das expectativas racionais." (Arida, 1984, p. 14). Isto posto, as condições ideais para a implementação da reforma são: inflação ser puramente inercial; o déficit operacional ser negligenciável; regras ou arranjos institucionais que impeçam o governo inflacionar depois da reforma.

A posição de Arida com relação ao déficit público neste momento parece um pouco condescendente. No entanto, posteriormente explica que à época foram influenciados pela ilusão estatística. De um lado, acreditava-se que o aumento da demanda de moeda com a monetização, induzida pela queda das taxas de inflação, permitiria o financiamento não inflacionário de um déficit público não muito grande. De outro, é importante lembrar que os dados referentes às contas fiscais não eram muito confiáveis. A proposta Larida expressava a crença que as precondiçóes fiscais estavam satisfeitas, ou seja, as contas fiscais estavam relativamente equilibradas quando se descontava o componente inflacionário do serviço da dívida. Depois do fracasso do Plano Cruzado, uma das lições seria a relevância do equacionamento da questão fiscal 
para viabilizar uma estabilização duradoura. A falta de ênfase no aspecto fiscal serviu de álibi para vários autores negarem o diagnóstico de inflação inercial. ${ }^{11}$ Sobre este assunto, declara Arida:

"... a titulo de registro histórico, observa-se que em cada plano brasileiro de estabilização, a equipe econômica estava consciente da necessidade de se promover um ajuste fiscal junto com a politica de rendas. No entanto, as estratégias diferiram. Durante o Plano Cruzado, o desequilibrio fiscal não foi abertamente enfatizado, num esforço de manter a credibilidade, o congelamento de preços foi apresentado como um primeiro passo que seria seguido pelos ajustamentos necessários. A equipe econômica esperava que o amplo apoio politico dado ao plano seria suficiente para tornar o ajuste fiscal viável. Em contrapartida, o desequilibrio fiscal foi reconbecido abertamente na implementação do Plano Verão. Os resultados práticos, entretanto, foram similares. $O$ ajuste fiscal do Cruzado foi recusado pelo Presidente, desejoso de segurar as medidas impopulares até as eleições marcadas para dez meses depois do início do plano. $O$ ajuste fiscal do Plano Verão foi bloqueado pelo Congresso por causa da grande desconfiança nas propostas administrativas. Em retrospectiva, parece claro que o período Sarney foi de um doloroso processo de aprendizado social. É injusto inferir da pobve performance fiscal que a equipe econômica em desenbar os programas de estabilização no Brasil foi indiferente à restrição orçamentária.”(Arida, 1991, p. 184).

No que se refere à futura âncora da moeda, Arida até então não tinha uma posição clara, uma vez que não se poderia prever qual seria a demanda de moeda numa economia estabilizada e consciente da fragilidade externa derivada da crise da dívida externa e constante escassez de divisas. Na verdade, ele chega a chamar de obscuro o significado de âncora num regime monetário fiduciário. Também não acredita que a mera fixação da taxa de câmbio garantiria o controle da emissão de moeda por parte do governo. Para contornar o problema da ancoragem, ele acaba sugerindo a manutenção da moeda indexada depois da reforma. Uma solução aventada foi ainda impor um teto legal para a expansão da nova moeda, para os diferentes conceitos de agregados monetários, inclusive os depósitos da Resolução 432, ${ }^{12}$ isto é, a âncora monetária e um regime de câmbio flutuante.

11 Barbosa e Simonsen (1989).

12 A Resolução 432 era um mecanismo que permitia às empresas privadas com passivos em doláres antecipar o pagamento da dívida no Banco Central, depositando o equivalente a esses débitos em moeda nacional, convertidos pela taxa de câmbio do dia. 
Williamson (1984), na sua avaliação da proposta Larida, considera a possibilidade da sugestão de Wicksell ${ }^{13}$ de administração da taxa de juros com o objetivo de manter a estabilidade de preços como alternativa à adoção de uma âncora nominal.

A idéia de Arida era não deixar os contratos indexados. A reforma era justamente para a transição de uma situação de inflação alta para o de inflação baixa. À época defendia uma taxa de juros real baixa pós-reforma monetária para viabilizar a volta do crescimento econômico. No entanto, a explosão do consumo após as tentativas de estabilização o levou a reconsiderar o papel da taxa de juros reais. Este será um dos aspectos centrais tratados na sua segunda tese de doutorado sobre inflação.

\section{Viabilidade Politica da Estabilização}

Depois de apresentar e defender a reforma monetária, Arida se preocupa com sua viabilidade política. Ou seja, era importante garantir a neutralidade distributiva mantendo a participação dos agentes na renda no nível pré-reforma e garantir que um novo choque distributivo não se manifestasse. Coloca-se então a pergunta sobre a necessidade, ou não, de um pacto social ${ }^{14}$ para viabilizar a reforma monetária. A negociação por meio de um acordo possibilitaria uma acomodação das demandas de diversos grupos pela participação na renda nacional compatível com o tamanho dela. Ainda dentro da discussão de pacto social, estabelecia uma diferenciação entre a necessidade de negociar pacto suave ou pacto forte. $\mathrm{O}$ primeiro se refere às medidas de políticas que provocam perdas temporárias a determinados grupos, mas há possibilidade de incluir cláusulas compensatórias. O pacto forte, por sua vez, torna-se necessário quando as perdas são permanentes ou contingentes aos desdobramentos do processo econômico. Neste caso, "não há garantia que os perdedores seriam compensados." (Arida, 1984, p. 19).

Quanto à reforma monetária com moeda indexada, Arida justifica a necessidade de um pacto social quase suave, por causa da presença de indexação dos contratos (salários, aluguéis, bens e serviços administrados pelo governo), que na reforma monetária precisariam ser pactuados novamente e convertidos pela média. O que parece perda no curto prazo, representará um ganho, principalmente quando se fala dos salários que sempre apresentam uma indexação com períodos de reajustes mais longos. Caso fossem corrigidos pelo pico, haveria um choque distributivo, decorrente da tentativa de os diversos grupos obterem uma participação na renda superior a um. Mas isto

13 Segundo Wicksell, as autoridades monetárias deveriam manter a estabilidade de preços, aumentando a taxa de juros acima de seu nível natural, quando há uma pressão para os preços subirem, e reduzi-la quando os preços tendem a cair. (Williamson, 1984, p. 173).

14 Para Arida, o conceito de pacto social será relevante se a implementação de políticas econômicas bemsucedidas depender da aceitação (ou não), por parte de certos grupos da sociedade, das perdas impostas pelas medidas adotadas. (Arida, 1984, p. 18). 
não significa que ninguém perde permanentemente. Um dos grandes perdedores lembrados, que daria uma característica de pacto forte para a reforma, seriam os bancos comerciais. Estes deixariam de ganhar a receita de floating.

Quando Arida foi perguntado sobre a experiência do Plano Cruzado, ele revela a alteração no princípio que deve estar na base de um processo de estabilização bemsucedido: o apoio político. Vale a pena repetir suas palavras,

"Na época era muito jovem, 33 anos. Padecia, penso que todos nós padeciamos, da falta de uma visão plena do processo de estabilização. Toda estabilização bem-sucedida tem que ter uma coalizão politica que apóie o núcleo-chave de politicas. Se não houver na partida um time econômico com idéias homogêneas, uma liderança politica clara e uma certa maturidade no mundo politico e na sociedade sobre o que é necessário fazer, não adianta tentar.[...] A solução Larida estava fora do horizonte intelectual da época, parecia mágica." (Arida, in Biderman, Cozac e Rego, 1996, p. 324-335).

\section{A VOLTA DOS "MÁGICOS"}

Como já salientado, pretende-se destacar nesta seção a mudança de ênfase na justificativa para a escolha da melhor estratégia de estabilização. Ademais, altera-se o tipo de argumentação de cunho político necessário para a garantia de um plano bem-sucedido. A viabilidade política significa não mais depender de um pacto social, mas, sim, da constituição de um grupo homogêneo sob liderança. Cabe destacar que Arida enfatiza que a implementação de um programa de estabilização é sempre um esforço coletivo.

Arida volta a participar da equipe econômica do governo em 1993, logo depois de Fernando Henrique Cardoso assumir o Ministério da Fazenda do governo Itamar Franco. Arida vai se juntar à equipe da qual já faziam parte Bacha e Lara Resende, que também participaram da experiência do Plano Cruzado. ${ }^{15}$ Fernando Henrique Cardoso era o quarto Ministro da Fazenda em onze meses de governo Itamar. Assim, o ambiente político era bastante conturbado. Segundo Arida,

"o clima de opinião vigente quando da posse de Fernando Henrique como ministro da Fazenda era muito pessimista. Quem quer que o reconstitua verá que na ocasião estávamos perdendo de goleada. É bem verdade

15 Outros economistas da PUC-RJ também participavam da equipe, como Gustavo Franco e Winston Fritsh. 
que éramos uma equipe homogênea, falando a mesma linguagem, com liderança e capacidade de ter um projeto politico cristalizados na figura do Fernando Henrique.[ ...] Estigmatizava-se quem quer que pensasse nos problemas de indexação e inércia como gente ignorante do óbvio: 'Eva tudo bobagem, não vamos mais cair nestas mágicas'...." (Arida, in Biderman, Cozac e Rego, 1996, p. 326, 338).

Apesar de o Plano Real retomar uma noção teórica anterior, Arida esclarece que entre o Plano Cruzado e o Plano Collor II a dinâmica da inflação havia se alterado e não era mais caracterizada pela inercialidade. "Daí o equívoco dos vários congelamentos subseqüentes ao Cruzado, de tentar corrigir e melhorar um modelo que se referia a uma realidade que não existia mais." (Biderman, Cozac e Rego, 1996, p. 339). Essa dinâmica só foi rompida na gestão convencional de política econômica praticada por Marcílio Marques Moreira em 1992. Para Arida, "após tantas tentativas de congelar preços e ativos financeiros, houve uma reação de horror à heterodoxia [...] A ironia da História é que foi justamente o dominio ideológico do saber convencional que tornou possivel utilizar a base conceitual do Larida para lançar o Plano Real." (Arida, 1999, p. 112-113). Mas a partir daí a inflação voltou a apresentar um forte caráter inercial, e uma solução de desindexação por meio da introdução de uma moeda indexada voltou a ser importante.

Em 1992, Arida se dedica a escrever sua tese de doutoramento durante quase nove meses. Da leitura da tese percebe-se que as características tão salientadas no período anterior, como justificando sua estratégia, foram abandonadas. Neste trabalho, ele se propõe a se concentrar em poucos aspectos referentes à estabilização, mas olha atentamente para as tentativas fracassadas. Entre 1986 e 1991 foram experimentados cinco programas de estabilização heterodoxos, cujos fracassos foram, em geral, debitados à persistência do déficit público. Mas esta não é a questão central de Arida. Sem minimizar a importância de equacionar a questão fiscal, sua preocupação é com a presença de cláusulas de indexação nos contratos financeiros e de trabalho que impõe especificidades ao programa de estabilização brasileiro. Ou seja, seu foco está na inércia inflacionária para o qual ele analiticamente distingue a partir de dois significados: "inércia pode descrever uma situação na qual a inflação permanece acima do nivel dado pelos fundamentos ou pode descrever uma situação na qual a resposta da inflação a choques ou a mudanças de políticas é lento."(Arida, 1992, p. 211).

A tese é claramente um trabalho mais conceitual e menos de proposituras que os anteriores, por sua natureza, mais sofisticado, além de apresentar um alto grau de abstração e nunca ter sido publicado. Parece um trabalho mais introspectivo, e não se preocupa em convencer como seus escritos da fase anterior procuram resolver questôes pendentes para uma proposta bem-sucedida de estabilização. Cabe destacar que ele insiste em lembrar que medidas ortodoxas, políticas monetária e fiscal apertadas, e he- 
terodoxas, de coordenação das decisões de preços, são complementares num programa de estabilização de uma inflação alta e crônica, caracterizada como inercial.

Depois de esclarecer na introdução que deixará de fora de sua análise aspectos importantes de qualquer programa de estabilização, ele apresenta três ensaios. O primeiro discute a indexação financeira e salarial. $O$ principal resultado de seu exercício, mesmo supondo o caso de uma inflação puramente inercial, é que:

"programas heterodoxos são expansionistas, mas violam a restrição externa se não acompanbados pela redução do estoque de divida doméstico.O paradigma inercial exagera o problema salarial e subestima o problema fiscal. O aumento do salário real de equilibrio causado pela estabilização torna o critério de neutralidade desnecessário mas o equilibrio orçamentário basta somente para um determinado estoque de divida. Os desenhos dos programas heterodoxos brasileiros não passam no teste de consistência no sentido de combinar o manuseio dos salários reais com a tentativa de eliminar a liquidez excessiva da divida doméstica." (Arida, 1992 , p. 7).

Deste primeiro ensaio, "Programas Heterodoxos e Incerteza da Taxa de Inflação", percebe-se que o paradigma conceitual de neutralidade, explícito e enfatizado na proposta "Larida", precisava ser revisto. ${ }^{16}$ Segundo Arida, em entrevista concedida a Biderman, Cozac e Rego, "depois da experiência do Plano Cruzado, da forte expansão de demanda que se seguiu imediatamente ao lançamento do Plano, cheguei à conclusão de que algo precisaria ser revisto.”(1996, p. 336) Verifica-se que a rápida redução das taxas de inflação quando da implementação do programa de estabilização heterodoxo provoca uma mudança de portfólio dos agentes econômicos, acarretando uma elevação na demanda agregada. A grande elevação na demanda agregada após várias tentativas de estabilização se apresentava como uma incógnita. Na verdade, a incerteza com relação às taxas de inflação faz os agentes manterem uma quantidade de títulos indexados superior à sua demanda na estabilidade. Ou seja, quanto maiores as taxas de inflação, maior a demanda por títulos indexados. Para Arida, seria esta a razão, o efeito absorção, para nunca se chegar à hiperinflação aberta. As conseqüências para o desenho do programa de estabilização, por exemplo, é a violação do princípio da neutralidade defendido anteriormente, mesmo supondo a inflação totalmente inercial. Como esclareceu na referida entrevista:

"o equilibrio real pós-reforma monetária tenderia ser diferente do equilibrio pré-reforma [..] a taxa real de juros necessária para assegurar

16 Arida (1991), numa nota de rodapé que comenta a questão da desindexação em um programa de estabilização, confirma a impossibilidade de se garantir a neutralidade do programa. 
estabilidade de preços tem que ser maior após a reforma que antes, e tão mais alta quanto mais endógena for a indexação dos contratos, e isso independentemente do déficit público."(Arida, in Biderman, Cozac e Rego, 1996, p. 336).

$\mathrm{Na}$ verdade, ele identifica que há um problema de liquidez excessiva da dívida pública. Assim, a estabilização bem-sucedida exige compensações para todos os efeitos da inflação alta sobre a demanda de ativos e poupança. Compensar as mudanças de alocação de portfólio devido à menor incerteza da taxa de inflação requer taxa de juros muito altas ou redução no estoque da dívida doméstica. Porém, altas taxas de juros não são sustentáveis no longo prazo. Assim, a estabilização sem suporte externo requer a redução no estoque de dívida doméstica. ${ }^{17}$ Neste aspecto, o apoio externo é fundamental, e vai além "da função tradicional de prover reservas internacionais para lastrear a moeda doméstica." (Arida, 1992, p. 124). A política de rendas é expansionista, mas se for canalizada poupança externa para o setor privado, equaciona-se a questão da conta corrente do balanço de pagamentos e há possibilidade de redução de dívida doméstica. É dentro dessa lógica que talvez se possa entender a rapidez com que foi conduzido o processo de privatização.

Esta preocupação com a dívida doméstica não aparece nas entrevistas, apenas em poucas páginas a título de "Comentários" de um trabalho apresentado em um Seminário ocorrido em janeiro de $1990 .{ }^{18}$ Este paper ${ }^{19}$ defendia, como mecanismo de consolidação de dívida, o seu alongamento compulsório. Arida vê dois argumentos que sustentam a consolidação, um primeiro, de natureza fiscal, e o segundo, com relação à decisão dos detentores de riqueza entre manter ativos indexados e ativos reais. Há também indícios de que esse tema foi debatido entre os membros da equipe econômica. Bacha, num evento comemorativo do segundo aniversário do Real, declarou que as características do sistema monetário brasileiro

"levou vários autores a acreditar que o Brasil teria de lidar com o problema de 'liquidez excessiva' [..] Este raciocinio levou a conclusão inevitável de que a supressão da liquidez dos fundos de curto prazo era um ingrediente necessário ao sucesso de um programa de estabilização. [..] O Plano Real optou por uma linha diferente de ataque ao problema [..] construir um consenso nacional em torno da necessidade de zerar o déficit operacional do orçamento como pré-condição para a estabilização.[..] Por fim, verificou-se que o problema de 'liquidez excessiva' não existe." Entretanto, mais a frente faz mais uma observação: "não há dúvida,

17 Arida (1992, p. 54).

18 Arida (1991).

19 Cardoso (1991) 
porém, de que a estratégia adotada no sentido de permitir a conversão voluntária da divida interna a taxas de juros de mercado foi muito mais onerosa em termos orçamentários do que a alternativa de forçar um alongamento compulsório do prazo da divida a taxas de juros fixas." (Bacha, 1995, p. 17, 18 e 19).

No segundo ensaio da tese, Arida faz um estudo analítico da reforma monetária do Plano Collor I que implementou um alongamento compulsório dos ativos financeiros. Neste caso, a reforma monetária foi desenhada para implementar um capital levy sobre a riqueza financeira líquida. Apesar de considerar uma maneira equivocada de estabilizar a inflação crônica brasileira, seu interesse é no funcionamento do sistema bimonetário vigente nos primeiros meses do plano. Reconhece que a comparação era complexa, mas foi um exercício importante. Lembra ainda que as percepções de liquidez excessivas da dívida moldaram diversas tentativas de estabilização anteriores. Esse estudo lhe permitiu "aguçar a intuição" no entendimento dos depósitos compulsórios como instrumento de política monetária. Segundo declarou: "cheguei à conclusão de que, apesar das ineficiências alocativas, seria preferivel praticar a politica monetária restritiva que a estabilização requer através de um blend de taxas de juros e depósitos compulsórios a utilizar a forma pura, ou seja, colocando todo o peso na taxa de juros." Assim, a compreensão do funcionamento do bloqueio dos ativos durante o Plano Collor foi fundamental.

"A engenhosidade da solução do Ibrabim Eris era evidente, mesmo sendo o bloqueio de ativos uma resposta equivocada à questão de como estabilizar. André e eu trabalbamos um tempo na conciliação analítica dos estoques de outside e inside money feita pelo Ibrabim, e este exercicio me ajudou muito quando da implementação da politica monetária restritiva do Plano Real, sem a qual, diga-se de passagem, o plano teria naufragado."(Biderman, Cozac e Rego, 1996, p. 336).

Foi também daí que surgiu a idéia de utilizar uma moeda virtual, e tirar a complexidade de permitir duas moedas circulando simultaneamente.

O terceiro ensaio da tese procura primeiro identificar os aspectos institucionais da inflação alta, e então isolar o mecanismo de indexação salarial. Para Arida, a negligência na assimilação do papel da indexação salarial no mecanismo de inércia da inflação sugere, com freqüência, aos analistas que é melhor retirar a indexação salarial com o programa de estabilização. ${ }^{20}$

20 Arida (1992, p. 179). 
Neste caso, torna-se fundamental avaliar qual é o mecanismo de indexação salarial mais apropriado à estabilização, principalmente na fase de transição do programa. Para tanto, discute basicamente os mecanismos de indexação salarial de periodicidade fixa e gatilho. Arida constata que os policy markers em geral, no Brasil, resistem a propostas de gatilho salarial por razões de ordem prática, pois uma vez definido um limite conveniente, haveria problemas apenas na ocorrência de choques do lado real. A inércia inflacionária advém da indexação com periodicidade fixa. Chama a atenção que o "problema de politica é a avaliação ex-ante da provável fonte de distúrbio que ocorrerá depois de implementado a estabilização." (Arida, 1992, p. 214).

Arida, na introdução da tese, afirma que a questão da necessidade de ajuste fiscal tem sido colocada de forma equivocada para a sociedade.

"De um lado, substituir o imposto inflacionário por tributos ordinários e ou cortes no orçamento e reduzir as transferências externas tende a estimular a atividade econômica. Estabilização também é provável que seja expansionista por causa das decisóes de investimento que são inibidas pela relativamente alta volatilidade de preços nos processos inflacionários crônicos. [...]. De outro lado, o efeito expansionista da estabilização faz a inflação um jogo de soma negativa. A retórica do alto sacrificio adotado nos programas pós-Cruzado inibe a formação de uma coalizão politica estável para sustentar a estabilização. Em ambientes de inflação crônica, a criação de um consenso politico sobre a reforma fiscal pode ser dificilmente obtidos pela desequilibrada ênfase sobre os custos do ajustamento fiscal. O argumento politico apropriado é que o policy makers que der sustentação à politica fiscal apertada se beneficiará politicamente da estabilização e não sofrerá com ela.”(Arida, 1992, p. 14-15).

Das considerações acima, percebe-se as dificuldades envolvidas quando da presença de indexação nos diferentes contratos. Os programas de estabilização não são neutros e, ainda, seus custos podem ser elevados, como revelou a opção por taxas de juros altas para lidar com a questão da dívida publica.

\section{OBSERVAÇÕES FINAIS}

Procurou-se, nas páginas anteriores, registrar, resumidamente, a contribuição e evolução da concepção de Arida sobre o processo de inflação alta e crônica experimentado na economia brasileira. Mesmo admitindo que o sucesso de um programa de estabi- 
lização é sempre resultado de um esforço coletivo, é inegável sua contribuição teórica para entender e propor soluções criativas para o caso brasileiro.

João Paulo Magalhães (1996, 1999) destaca que os desenvolvimentos teóricos heterodoxos em torno do debate da inflação crônica constituem uma importante contribuição de interpretação e formulação de política econômica adaptados à realidade e às especificidades de países menos desenvolvidos. Considera uma adaptação bemsucedida de um paradigma válido para as economias maduras que marcou o pensamento econômico brasileiro na década de 1980. Apesar de não ser possível negar que os processos inflacionários crônicos se apresentavam como uma característica de economias menos desenvolvidas, no debate, segundo Magalhães (1996), desaparece o vínculo entre inflação e desenvolvimento, traço marcante nos trabalhos de tradição Cepalina.

Uma analista arguta, Maria da Conceição Tavares, em entrevista a Haddad reconhece a engenhosidade da solução via reforma monetária com moeda indexada. E mais, percebe sua dimensão política. Vale a pena, para finalizar, reproduzir este trecho da entrevista:

"O Real é uma decorrência de duas coisas. Em primeiro lugar, a idéia teórica da URV era muito interessante. Segundo os mentores do Plano, seria possível fazer a convivência de duas moedas em que a velha iria ser destruida pela hiperinflação e substituida pela nova. Seria um caso de uma hiperinflação programada, coisa que ninguém nunca se atreveu a executar. Foi original mesmo, não bá a menor dúvida. Estudaram o fenômeno da hiperinflação no mundo, verificaram o que aconteceu com a moeda nos vários paises e descobriram que todos se ancoraram na moeda mais forte internacionalmente. Todos tiveram também problema fiscal. Ai começou a discussão de uma segunda questão: se fazia o ajuste fiscal ou não. Os mais ortodoxos, como Edmar Bacha, queriam primeiro fazer o ajuste fiscal. Aparentemente, o André Lara Resende e o Persio Arida, que tinham feito o modelo, topavam fazer a convivência das duas moedas, a indexada - URV - e o cruzeiro velho. Mas queriam que fosse um processo longo, porque o modelos deles requeriam a destruição completa da moeda velha e a urvização ou dolarização completa da economia, para então mudar o padrão monetário. Eles achavam muito arriscado fazer no meio. Dai vem o prestígio do Gustavo Franco, porque ele, que é apenas um discípulo menor da escola e não tinha feito teoria nenhuma, percebeu que isso era impossivel politicamente, dada a proximidade das eleições. Enquanto o Persio e o Lara, de um lado, e o Bacha, de outro, se enfrascaram em discussões intermináveis, o plano não ia para lugar 
nenhum. O dilema eva: faz logo ou espera até o fim do ano? Em menos de um ano, segundo eles, o modelo não acertaria os preços relativos, sobretudo da relação entre tradables e non-tradables e a desindexação não estaria completa, podendo contaminar a moeda nova. Ai o Gustavo ganhou, com o apoio interessado do Fernando Henrique, que queria eleger-se de qualquer maneira. Mas cometeu o 'pecado mortal' de entrar na reforma monetária deixando sobrevalorizar o real nominalmente até outubro, quando um Real valia muito mais que um dólar, [...] com exceção dos aluguéis e dos serviços, é claro que a massa fica contentona! Foi o que o Gustavo Franco prometeu ao presidente: 'Com esse plano, eu não só garanto que o senhor ganha como vou lhe dar dois anos de tranqüilidade, porque temos capacidade de absorção de recursos externos de até 2,5\% do PIB.'Ai é que ele errou estrondosamente." (Tavares, 1998, p. 156-157).

Persio Arida deixa a Presidência do Banco Central em julho de 1995 em decorrência de sua discordância quanto à condução da política cambial. A alteração no regime cambial, com a adoção do sistema de bandas, foi introduzido em março daquele ano. Segundo Arida, "já em 1995 propus evoluir para uma banda larga, passo prévio para a adoção de um câmbio inteiramente flutuante." (Arida, 1999a). No entanto, venceu a proposta de bandas estreitas defendida por Gustavo Franco, então Diretor de Assuntos Internacionais, que em agosto de 1997 assumiria a Presidência do Banco.

\section{BIBLIOGRAFIA}

Arida, Persio. Economic stabilization in Brazil. Texto para Discussão, n. 84, Departamento de Economia PUC/RJ, dezembro. (publicado como Working Paper 149 of Wilson Center, Washington, DC, USA, november, 1984), 1984.

. Macroeconomic issues for Latin América. Texto para Discussão, n. 87, Departamento de Economia PUC/RJ, março, 1985.

. Neutralizar a inflação, uma idéia promissora. In: Rego, J. M., Inflação inercial, teorias sobre inflação e Plano Cruzado. Rio de Janeiro: Paz e Terra, 1986. (Originalmente publicado em Economia e Perspectiva, Boletim do Conselho Regional de Economia, setembro de 1984).

. Comments. In: Bruno, M.; Fischer, S.; Helpman, E.; Liviatan, N. (orgs.), Lessons of economic stabilization and its aftermath. The MIT Press, 1991, p. 178186. (Conference held at the Mishkenot Sha' ananim Music Center in Jerusalem, jan. 1990, and sponsored by the Bank of Israel and the Inter-American Development Bank, 1991). 
. Essays on Brazilian stabilization programs. 1992. Tese (Doutorado), MIT. Mimeografado.

. A história do pensamento econômico como teoria e retórica. In: Rego, J. M. (org.), Retórica na economia. São Paulo: Editora 34, 1996. Segunda versão (1984) do texto com o mesmo título (de 1983) publicado originalmente como "Texto para Discussão no. 54" pelo Departamento de Economia da PUC/RJ, 1996.

. Observações sobre o Plano Real. Economia Aplicada, v. 3, n. especial, p. 109-115, março 1999.

. Do pretérito ao futuro. Jornal O Estado de São Paulo, $5^{\text {a }}$.feira, 21 de janeiro de 1999. wwwl.estado.com.Br/jornal/99/01/21/news064.htm, 1999a.

. In: Bierdeman, Ciro, Cozac, L.; Rego, J. M. Conversas com economistas brasileiros. São Paulo: Editora 34, 1996.

Arida, Pérsio; Lara Resende, André. Inertial inflation and monetary reform in Brazil. Paper prepared for the Conference "Inflation and Indexation" Institute of International Economics, Washington. D. C., December, 6-8, 1984. Publicado no Brasil como Texto para discussão do Departamento de Economia PUC/RJ, n. 85, janeiro 1985 .

Bacha, Edmar. Plano Real: uma primeira avaliação. Revista do BNDES, v. 2, n. 3, p. 3-26, junho 1995.

Barbosa, Fernando de H.; Simonsen, Mario. H. (orgs.), Plano Cruzado: inércia x inépcia. Rio de Janeiro: Editora Globo,1989.

Bier, André; Messemberg, Roberto; Paulani, Leda. O choque heterodoxo e o pós-moderno: o Cruzado em conflito. São Paulo: Paz e Terra, 1987.

Cardoso, Eliana. From inertia to megainflation: Brazil in the 1980s. In: Bruno, M.; Fischer, S.; Helpman, E.; Liviatan, N., Lessons of economic stabilization and its aftermath. The MIT Press, 1991, p. 143-177.

Dornbusch, Rudiger. Coments, Brasil. Conference "Inflation and Indexation". Washington. D. C.: Institute of International Economics, December, 6-8, 1984, p. 45-55.

Fernadez, Ramón. Retórica y economia: argumentos a favor del pluralismo y de la conversación civilizada. In: Metodologia de las Ciencias Sociales: logica, lenguaje y racionalid. Buenos Aires: Ediciones Macchini, 1999.

Lopes, Francisco L. Só um choque heterodoxo pode derrubar a inflação. Economia em Perspectiva, Corecon-SP, agosto 1984.

Magalhães, João P. A. Vinte anos de pensamento econômico no Brasil. In: Elias, L. A.; Mineiro, A. S.; Magalhães, J. P. A (orgs.), Vinte anos de politica econômica. Rio de Janeiro: Editora Contraponto, 1999.

- Paradigmas econômicos e desenvolvimento - a experiência brasileira. Rio de Janeiro: Editora UFRJ e Ed. UERJ, 1996. 
Sargent, Thomas. Os finais de quatro hiperinflações. In: Rego (org.), Inflação inercial, teorias sobre inflação e o Plano Cruzado. Rio de Janeiro: Editora Paz e Terra, 1986. Publicação em inglês 1982.

Sola, Lourdes. Choque heterodoxo e transição democrática sem ruptura: uma abordagem transdisciplinar. In: Sola, L. (org.), O estado da transição: política econômica na Nova República. São Paulo: Vértice, Editora Revista dos Tribunais, 1988.

Tavares, Maria C. Poder, dinheiro e vida intelectual. Entrevista concedida a Haddad, F. Teoria e Debate, n. 37, mar-abr-maio, 1998.

Williamson, John. Concluding appraisal. Conference "Inflation and Indexation". Washington. D. C.: Institute of International Economics, December, 6-8, 1984, p. 167-178. 